\title{
Implicações nutricionais com base em diferentes intensidades de colheita da biomassa de Eucalyptus urophylla $\mathrm{x}$ Eucalyptus globulus
}

\author{
Nutritional implications based in different intensities of Eucalyptus urophylla $\mathbf{x}$ Eucalyptus globulus \\ biomass harvesting
}

\author{
Márcio Viera ${ }^{\mathrm{I}}$ Mauro Valdir Schumacher ${ }^{\mathrm{II}}$ Peter Trüby' ${ }^{\mathrm{III}}$ Elias Frank Araújo ${ }^{\mathrm{IV}}$
}

\section{RESUMO}

A disponibilidade de nutrientes para futuros plantios em um sítio florestal está relacionada principalmente à, intensidade de colheita aplicada. Objetivou-se, com este estudo, avaliar as implicações nutricionais causadas pelas diferentes intensidades de colheita da biomassa de um povoamento de Eucalyptus urophylla $x$ Eucalyptus globulus com dez anos de idade, em Eldorado do Sul - RS. A avaliação das implicações nutricionais conforme a intensidade de colheita florestal foi analisada levando em consideração: o estoque de nutrientes entre o sistema solo - planta; os efeitos da colheita dos diferentes componentes da biomassa acima do solo na remoção dos nutrientes; o número de rotações e a taxa de remoção de nutrientes conforme o sistema de colheita utilizado e o coeficiente de utilização biológica dos nutrientes. Com a colheita da madeira com casca, todos os nutrientes teriam uma remoção superior a $45 \%$ de sua quantidade acumulada na biomassa total acima do solo. Entretanto, removendo apenas a madeira comercial, que apresenta o maior coeficiente de utilização de nutrientes, a porcentagem de remoção para os nutrientes, com exceção do Cu e Zn, seria inferior a $50 \%$, chegando até $10 \%$ no caso do Ca, em relação ao total contido na biomassa. O fósforo $e$ o cálcio poderão ser os principais nutrientes a tornaremse limitantes na produtividade nas próximas rotações, pois as estimativas de rotações potenciais estão próximas a um, quando realizada a colheita da madeira com casca.

Palavras-chave: produção florestal, estoque de nutrientes, disponibilidade de nutrientes.

\section{ABSTRACT}

Nutrients available for future plantation is mainly related to the harvest system applied. Based on this, this study aimed to assess the nutritional implications caused by difference biomass harvest intensities in the Eucalyptus urophylla $x$
Eucalyptus globulus 10 years-old in Eldorado do Sul - RS. Nutritional implications assessment was analyzed and taken into account: nutrients balance between soil-plant system; harvest effects of the different aboveground components in the nutrients removal; rotation numbers and nutrients removal rate in relation to harvest system used and nutrients biological utilization rate. With the harvest of wood with the bark all the nutrients removal would suffer more than $45 \%$ of the total amount accumulated in aboveground biomass. However, removing just the wood, which has the highest nutrients utilization rate, the nutrients removed percentage, except by $\mathrm{Cu}$ and $\mathrm{Zn}$, will be less than $50 \%$ and up to $10 \%$ in the case of $\mathrm{Ca}$ in relation to the total biomass contained. Phosphorus and calcium can be the main nutrients which become limited in the next rotation productivity, because the potential rotation estimates are close to one, when wood with bark are harvested.

Key words: forestry production, nutrients stock, nutrients available.

\section{INTRODUÇÃO}

A quantificação dos nutrientes nos componentes da biomassa de um povoamento florestal permite avaliar a magnitude dos reflexos que seriam causados pela intervenção antrópica ou por fenômenos naturais ocorridos no ecossistema. Em florestas manejadas para a produção de biomassa de madeira, a retirada desse componente é o principal meio de exportação de nutrientes (DRUMOND et al., 1997). Entretanto, para a produção de biomassa energética, o manejo adotado pode levar em

IDepartamento Multidisciplinar, Universidade Federal de Santa Maria (UFSM), Campus Silveira Martins, 97195-000, Silveira Martins, RS, Brasil. E-mail: vieraflorestal@yahoo.com.br. Autor para correspondência.

IIUFSM, Centro de Ciências Rurais (CCR), Santa Maria, RS, Brasil.

IIIUniversidade de Freiburg, Freiburg, Alemanha.

${ }^{\text {IV }}$ Celulose Rio-Grandense (CMPC), Guaíba, RS, Brasil. 
consideração a colheita total da árvore e, em casos extremos, a remoção da serapilheira acumulada e do sub-bosque.

O conhecimento da taxa de exportação de nutrientes conforme a intensidade de colheita da biomassa é um requerimento essencial para empreendedores florestais, com vistas à adoção de técnicas de conservação e reposição de nutrientes no ecossistema (SANTANA et al., 1999). Esse conhecimento é necessário para que sejam tomadas as medidas adequadas de monitoramento, pois plantações manejadas inadequadamente poderão gerar impactos severos sobre os ciclos da água, dos nutrientes e sobre o equilíbrio ecológico dos ecossistemas naturais adjacentes (POGGIANI et al., 1998). Dessa forma, o estudo desses povoamentos, em especial no que diz respeito à exportação de nutrientes através da colheita da biomassa, é a base para o entendimento da dinâmica nutricional em uma plantação. No caso de plantios em áreas sem tradição silvicultural, é vital para a produção contínua e sustentada, possibilitando a previsão de situações que poderiam ser críticas a médio e longo prazo, tanto em relação à produtividade, como em relação às características químicas do solo.

A remoção de nutrientes pela colheita florestal, segundo COBB et al. (2008), seria um dos fatores a ser considerado, devido à preocupação com a manutenção da produtividade dos sítios, principalmente em condições de baixo suprimento de elementos essenciais às árvores pelo solo. Nesse sentido, explorações intensivas em rotações curtas, sem previsão de um período mínimo necessário para reposição de nutrientes, têm sido apontadas como as maiores responsáveis pelo exaurimento químico do solo. Portanto, ter o conhecimento da exportação de nutrientes através dos diferentes componentes das árvores é importante para a compreensão de um manejo conveniente do ponto de vista nutricional (SCHUMACHER \& POGGIANI, 1993). Com isso, o presente estudo objetivou avaliar as implicações nutricionais causadas pela simulação de diferentes intensidades de colheita de um povoamento de Eucalyptus urophylla x Eucalyptus globulus com dez anos de idade.

\section{MATERIAL E MÉTODOS}

O estudo foi realizado em um plantio híbrido de Eucalyptus urophylla x Eucalyptus globulus em Eldorado do Sul - RS, situado na coordenada geográfica central de $30^{\circ} 10^{\prime} 31.21^{\prime \prime}$ de latitude Sul e $51^{\circ} 36^{\prime} 17.85^{\prime \prime}$ de longitude Oeste. O solo na área experimental é um Argissolo Vermelho Distrófico típico (STRECK et al., 2008). A implantação do povoamento foi realizada por meio de preparo reduzido do solo com escarificação até uma profundidade média de $40 \mathrm{~cm}$, durante o mês de julho de 2001. O espaçamento utilizado foi de $3,5 \mathrm{mx} 2,5 \mathrm{~m}$. Foi realizada adubação de plantio com aplicação de $300 \mathrm{~kg} \mathrm{ha}^{-1}$ de fosfato reativo e $100 \mathrm{~g}$ planta $^{-1}$ de NPK 06:30:06, conforme a análise do solo e recomendação de adubação. Foram efetuadas duas adubações de cobertura: uma aos três meses, após implantação, com adição de 150 g planta $^{-1}$ de NPK 15:05:30, e outra aos 12 meses de idade das plantas, com a mesma formulação e dose da anterior. Cabe ressaltar que não foi realizada a adição de calcário na área.

A quantificação da biomassa e dos nutrientes acima do solo foi realizada aos dez anos de idade do povoamento. Demarcaram-se quatro parcelas de $35 \mathrm{~m} \times 20 \mathrm{~m}$, nas quais foram realizadas as medições de diâmetro à altura do peito (DAP), com o auxilio de uma fita diamétrica, e de altura total, com hipsômetro Vertex III. Mediante o inventário florestal, os indivíduos foram classificados em cinco classes diamétricas $(9,1-13,0 ; 13,1-17,0 ; 17,1-21,0 ; 21,1-$ 25,0 e 25,1-29,0cm). A determinação da biomassa do eucalipto baseou-se na amostragem de 15 árvores, 3 em cada classe diamétrica. Uma vez identificadas as árvores, elas foram abatidas e fracionadas nos componentes: folhas; galhos; casca da madeira comercial; e madeira comercial (diâmetro $\geq 6,0 \mathrm{~cm}$ ). Fuste com diâmetro inferior a $6 \mathrm{~cm}$ foi considerado como fração galhos. As frações foram pesadas em balança com precisão de $100 \mathrm{~g}$, para a obtenção da biomassa úmida total. Para estimar a biomassa e os nutrientes, coletaram-se amostras dos diferentes componentes, procedendo-se da seguinte forma: para os componentes folha e galho, foi coletada uma amostra por árvore. Em relação à madeira e à casca, a amostragem procedeu-se da seguinte maneira: distribuíram-se três pontos de amostragem no percorrer do comprimento do fuste comercial, nas posições medianas das secções resultantes da divisão em três partes iguais. Após a amostragem de cada componente, o que correspondia a $150 \mathrm{~g}$ de massa úmida de cada, eles foram colocados em embalagens de papel pardo, devidamente identificadas e posteriormente postas para secagem em estufa de circulação e renovação de ar a $70^{\circ} \mathrm{C}$, até atingirem peso seco constante, sendo, então, determinada a massa seca em balança digital de precisão $(0,01 \mathrm{~g})$. A estimativa da biomassa do eucalipto foi realizada com base no ajuste de equações de regressão. Os diferentes componentes da biomassa acima do solo 
(folha, galho, casca e madeira) foram considerados variáveis dependentes, e as variações e combinações do diâmetro à altura do peito e altura total, variáveis independentes. Utilizou-se o aplicativo SPSS 13.0 for Windows (1996) para a modelagem, seguindo procedimento stepwise. A estimativa da biomassa por hectare foi realizada por meio da aplicação das equações de regressão com os dados do inventário florestal e extrapolação com base na área da parcela. $\mathrm{Na}$ tabela 1, pode-se verificar as equações ajustadas e as estatísticas dos modelos.

Para a determinação da biomassa do sub-bosque, foram demarcadas cinco parcelas de $5,0 \mathrm{~m} \times 5,0 \mathrm{~m}\left(25 \mathrm{~m}^{2}\right)$ no interior do povoamento de eucalipto. Toda vegetação encontrada no interior de cada uma das parcelas, com exceção das plantas de eucalipto, foram quantificadas quanto à biomassa acima do solo. A estimativa da biomassa de subbosque por hectare foi extrapolada com base na biomassa seca por parcela. A serapilheira acumulada sobre o solo foi quantificada por meio da coleta de 16 amostras, utilizando-se uma moldura de madeira com formato quadrático e com $25 \mathrm{~cm}$ de lado. Após secagem $\left(70^{\circ} \mathrm{C}\right)$ e pesagem, as amostras foram moídas em moinho tipo Willey com peneira de 30 mesh, para posterior determinação dos teores de nutrientes. As análises de nutrientes foram realizadas no Institut für Bodenkunde und Waldernährungslehre da Universidade Albert - Ludwigs (Freiburg, Alemanha), onde se efetuou a determinação de N, P, $\mathrm{K}, \mathrm{Ca}, \mathrm{Mg}, \mathrm{S}, \mathrm{Cu}, \mathrm{Fe}, \mathrm{Mn}$ e $\mathrm{Zn}$. O nitrogênio total foi determinado por via seca no aparelho denominado CNS - Analysator Carlo Erba NA 1500. Os demais nutrientes foram obtidos por meio de digestão em ácido $\mathrm{HNO}_{3}(65 \%)$ e posterior determinação no ICP (Inductively Coupled Plasma).

A amostragem do solo, para análise química e densidade, foi realizada por meio da abertura de nove trincheiras de $1,0 \mathrm{mx} 1,0 \mathrm{mx} 1,3 \mathrm{~m}$.
As análises dos nutrientes disponíveis no solo foram determinadas por meio do ICP e do $\mathrm{N}$ total pelo CNS - Analysator Carlo Erba NA 1500.

Com base na biomassa e no estoque de nutrientes no eucalipto e no sub-bosque e o estoque de nutrientes no solo, pode-se avaliar as implicações nutricionais conforme a intensidade de colheita aplicada. Para isso, levou-se em consideração o balanço de nutrientes entre o sistema solo - planta, os efeitos da colheita dos diferentes componentes da biomassa acima do solo na remoção dos nutrientes, o número de rotações e a taxa de remoção de nutrientes, conforme a intensidade de colheita utilizada e o coeficiente de utilização biológica dos nutrientes.

O cálculo do número potencial de rotações (NPR, $\mathrm{kg}$ de nutrientes que permanece no sítio/kg de nutrientes removido do sítio) de 10 anos para o Eucalyptus urophylla x E. globulus, conforme a intensidade de colheita, foi realizada levando em consideração a colheita de toda a biomassa acima do solo $\left(\mathrm{NPR}_{\text {total }}\right)$, a colheita da árvore inteira de eucalipto $\left(\mathrm{NPR}_{\text {eucalipto }}\right)$, a colheita da biomassa de madeira e casca do eucalipto $\left(\mathrm{NPR}_{\text {madeira }}+\right.$ casca $)$ e a colheita da biomassa de madeira do eucalipto $\left(\mathrm{NPR}_{\text {madeira }}\right)$, adaptadas da metodologia de número potencial de cortes proposta por BARROS et al. (1986). A taxa de remoção de nutrientes (TR, kg de nutrientes $\mathrm{Mg}$ de biomassa $^{-1}$ ) foi obtida levando em consideração as mesmas intensidades de colheita descrita anteriormente $\left(\mathrm{TR}_{\text {total }}, \mathrm{TR}_{\text {eucalipto }}, \mathrm{TR}_{\text {madeira }+}\right.$ casca $\left.\mathrm{e} \mathrm{TR}_{\text {madeira }}\right)$. O coeficiente de utilização biológica (CUB) de nutrientes foi obtido pela razão entre a quantidade de biomassa e nutrientes, ambos com a mesma unidade. $\mathrm{O}$ estoque de nutrientes no solo, na forma disponível (P, K, Ca e Mg) e total $(\mathrm{N})$, foi determinado com base no teor desses elementos em diferentes profundidades do solo $(0-25 ; 25-50 ; 50-75$ e $75-100 \mathrm{~cm}$ ) e na densidade do solo (Tabela 2 ).

Tabela 1 - Equações e estatísticas dos modelos de ajuste das equações de regressão utilizadas para estimar a biomassa em um povoamento de Eucalyptus urophylla x Eucalyptus globulus, Eldorado do Sul, RS.

\begin{tabular}{|c|c|c|c|c|c|c|c|}
\hline Comp. & Equações & $\mathrm{b}_{0}$ & $\mathrm{~b}_{1}$ & $b_{2}$ & $b_{3}$ & $\mathrm{R}_{\text {aj. }}^{2}$ & Syx \\
\hline Madeira & $\ln y=b_{0}+b_{1} \cdot H+b_{2} \cdot\left(H^{3} \cdot D_{A P}{ }^{-1}\right)+b_{3} \cdot D_{A P}{ }^{-1}$ & 2,139 & 0,163 & $-0,001$ & $-13,155$ & 0,998 & 0,038455 \\
\hline Casca & $\operatorname{lny}=b_{0}+b_{1}$. DAP & 0,001 & 0,137 & - & - & 0,954 & 0,164477 \\
\hline Galhos & $y=b_{0}+b_{1} \cdot\left(\right.$ DAP. $\left.H^{-1}\right)+b_{2} \cdot\left(H \cdot D A P^{-1}\right)$ & $-333,838$ & 268,221 & 107,793 & - & 0,920 & 0,999190 \\
\hline Folhas & $\ln y=b_{0}+b_{1} \cdot\left(D P^{2} \cdot H^{-1}\right)$ & 0,137 & 0,075 & - & - & 0,858 & 0,151308 \\
\hline Total & $\ln y=b_{0}+b_{1} \cdot H+b_{2} \cdot \ln D A P$ & $-0,566$ & 0,071 & 1,289 & & 0,997 & 0,042609 \\
\hline
\end{tabular}

em que: $\ln =$ logaritmo natural; $y=$ variável dependente (biomassa em kg por árvore); $b_{0}, b_{1}, b_{2}$ e $b_{3}=$ coeficientes da equação de regressão; $\mathrm{DAP}=($ diâmetro à altura do peito $-\mathrm{cm}) ; \mathrm{H}=$ altura total $(\mathrm{m}) ; \mathrm{R}_{\text {aj. }}^{2}=$ coeficiente de determinação ajustado; Syx $=$ erro padrão absoluto da estimativa. 
Tabela 2 - Atributos químicos do solo na área experimental, localizada no município de Eldorado do Sul, Rio Grande do Sul.

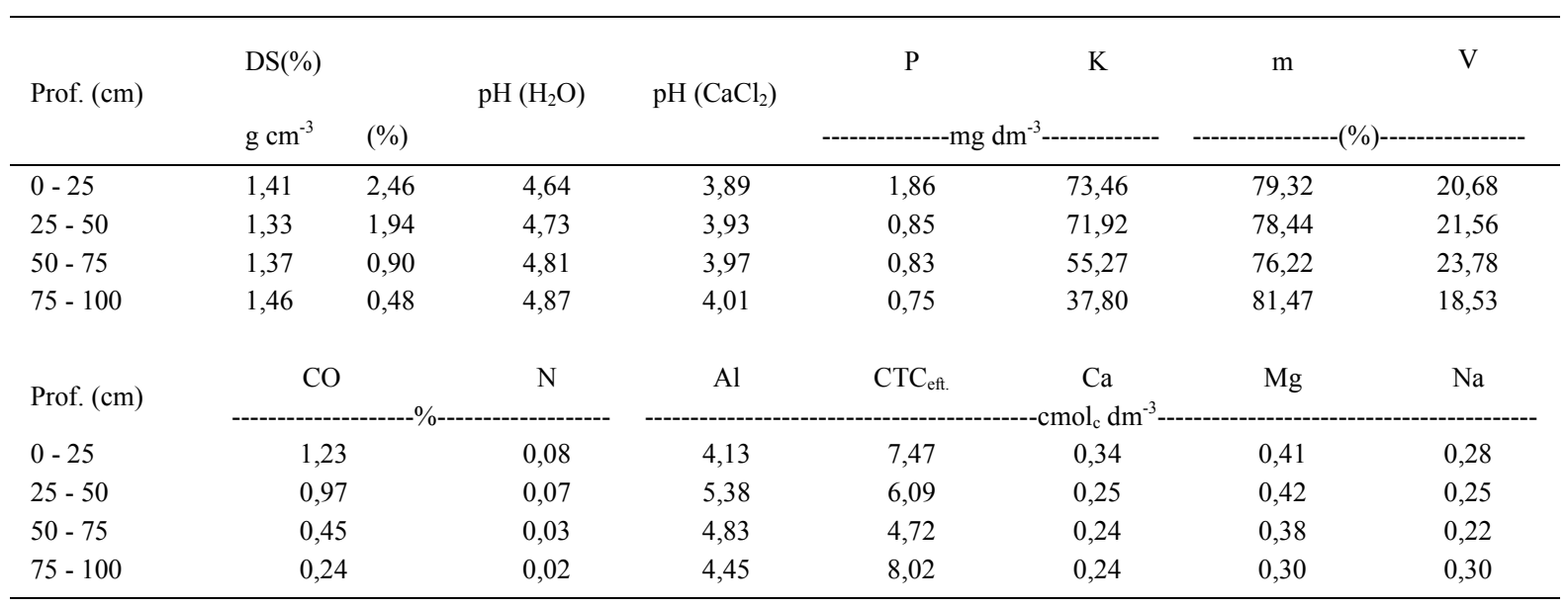

\section{RESULTADOS E DISCUSSÃO}

A distribuição dos nutrientes nos componentes da árvore (Figura 1) tem grande importância na nutrição de povoamentos florestais manejados em rotações sucessivas, pois o manejo intensivo pode aumentar significativamente a produção de biomassa, aumentando também a exportação de nutrientes do sítio (VIERA et al., 2011). Observa-se que, mesmo a fração folhas apresentando a menor biomassa, ela contém elevado estoque de nutrientes, como, por exemplo, de nitrogênio $(66 \mathrm{~kg}$ $\left.\mathrm{ha}^{-1}\right)$. Considerando a colheita da árvore inteira (biomassa acima do solo), a remoção de nutrientes seria superior a $80 \%$ para o P e o K; superior a $70 \%$ para o $\mathrm{Ca}, \mathrm{Mg}, \mathrm{S}$, Cu e Zn; superior a $60 \%$ para $\mathrm{Ne} \mathrm{Mn}$; e superior a $20 \%$ para o Fe (Figura 2). Cabe ressaltar que a serapilheira acumulada apresenta contaminação com Fe, mascarando as taxas de remoção. $\mathrm{O}$ efeito da contaminação do material em contato com o solo é relatado por VIERA et al. (2010) analisando a concentração de nutrientes na serapilheira acumulada em um fragmento de Floresta Estacional Decidual, onde verificaram teores elevados de $\mathrm{Fe}$ e $\mathrm{Mn}$. Os autores salientam que o processo de separação das impurezas é muito complexo, devido ao processo de decomposição e fragmentação do material analisado.

A colheita madeira + casca, muitas vezes, é utilizada pela indústria de base florestal, onde a madeira é a matéria-prima para a produção de celulose e papel e a casca é utilizada em caldeiras como fonte energética. Utilizando-se essa intensidade de colheita, a remoção de nutrientes chegaria a uma porcentagem de $71 \%$ do $\mathrm{K}$; $66 \%$ do $\mathrm{Ca}$ e $\mathrm{Zn}$; $63 \%$ do
P; $61 \%$ do $\mathrm{Mg} ; 57 \%$ do S; $47 \%$ do $\mathrm{N}$ e $45 \%$ do $\mathrm{Mn}$. Dessa forma, todos os nutrientes sofreriam remoção superior a $45 \%$ de sua quantidade acumulada na biomassa total acima do solo. Contudo, removendo apenas a madeira comercial e deixando a casca no sítio florestal, a porcentagem de remoção para os nutrientes, com exceção do $\mathrm{Cu}$ e $\mathrm{Zn}$, seria inferior a $50 \%$, chegando até $10 \%$ no caso do $\mathrm{Ca}$, em relação ao total contido na biomassa (Figura 2). Em termos de comparação, a quantidade de fertilizantes que se deixa de aplicar pelo simples fato de retirar somente o componente madeira na colheita chega a $762,64 \mathrm{~kg} \mathrm{ha}^{-1}$ de ureia $(45 \%$ de N), 153,08kg ha-1 de superfosfato triplo $\left(46 \%\right.$ de $\left.\mathrm{P}_{2} \mathrm{O}_{5}\right)$ e $466,30 \mathrm{~kg} \mathrm{ha}^{-1} \mathrm{de}$ cloreto de potássio $\left(60 \%\right.$ de $\left.\mathrm{K}_{2} \mathrm{O}\right)$.

$\mathrm{O}$ fósforo e o cálcio poderão ser os principais nutrientes a se tornarem limitantes na produtividade nas próximas rotações, pois as estimativas de rotações estão próximas a um, com a colheita da madeira com casca (Tabela 3). Adotando um sistema de manejo que possibilite a permanência da casca no sítio e a retirada apenas da madeira, o número potencial de rotações seria aumentado, principalmente, em consideração ao aumento da disponibilidade de Ca. Segundo SANTANA et al. (2002), essa intensidade de colheita seria a mais adequada, pois a maioria dos solos cultivados com povoamentos de eucalipto apresenta baixos teores de $\mathrm{Ca}$ e, em alguns casos, mais de $60 \%$ do total desse elemento absorvido pela biomassa acima do solo é exportado pela retirada da casca do sítio através da colheita florestal. Nesse sentido, na utilização de uma prática de colheita com exploração da casca, o Ca será o nutriente com maior risco de limitação da 


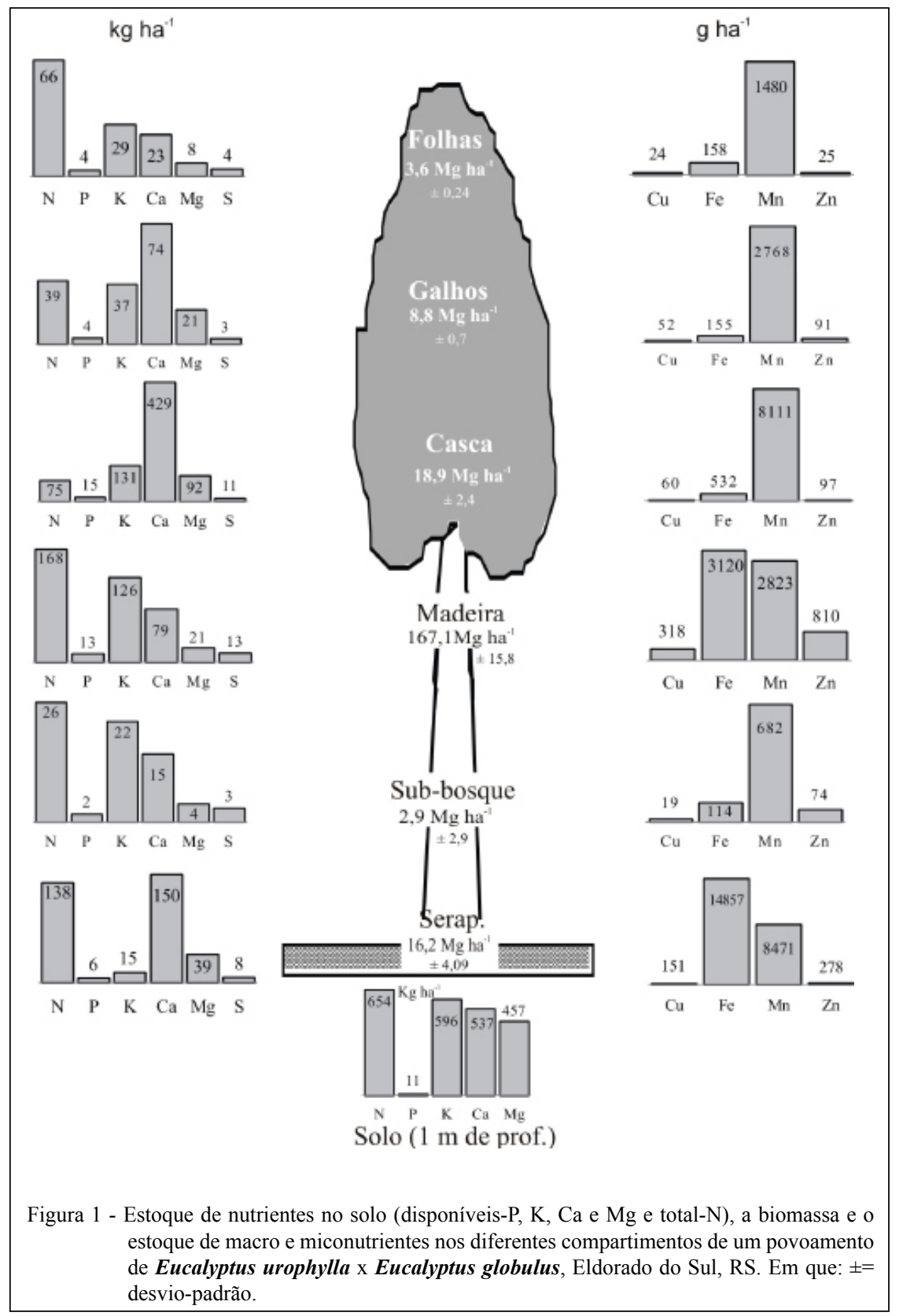

produtividade, seguido pelo $\mathrm{K}, \mathrm{N}$ e $\mathrm{Mg}$. No entanto, em função da diferença de sensibilidade ao método de colheita por parte dos nutrientes, esse cenário pode ser alterado por meio da modificação da intensidade de colheita.

Dependendo da intensidade de exploração adotada, ocorrerá variação na taxa de remoção de nutrientes (Tabela 3). Quando realizada apenas a retirada da madeira, a redução será marcante, principalmente para o cálcio. A menor taxa de remoção de nutrientes pela colheita da madeira está relacionada aos baixos teores de nutrientes nesse componente e ao maior estoque de biomassa. Essa alteração no manejo florestal implica maior sustentabilidade do ecossistema (SANTANA et al., 1999). A colheita da biomassa de madeira com casca apresenta a seguinte magnitude de remoção de nutrientes: $\mathrm{Ca}>\mathrm{K}>\mathrm{N}>\mathrm{Mg}>\mathrm{P}>\mathrm{S}$ (Figura 1). Efetuandose a colheita apenas da madeira, a taxa de remoção de nutrientes seria reduzida para todos os elementos, e a magnitude de remoção seria: $\mathrm{N}>\mathrm{K}>\mathrm{Ca}>\mathrm{Mg}>\mathrm{P}=\mathrm{S}$. A magnitude de remoção de nutrientes, tanto para

Ciência Rural, v.45, n.3, mar, 2015. 


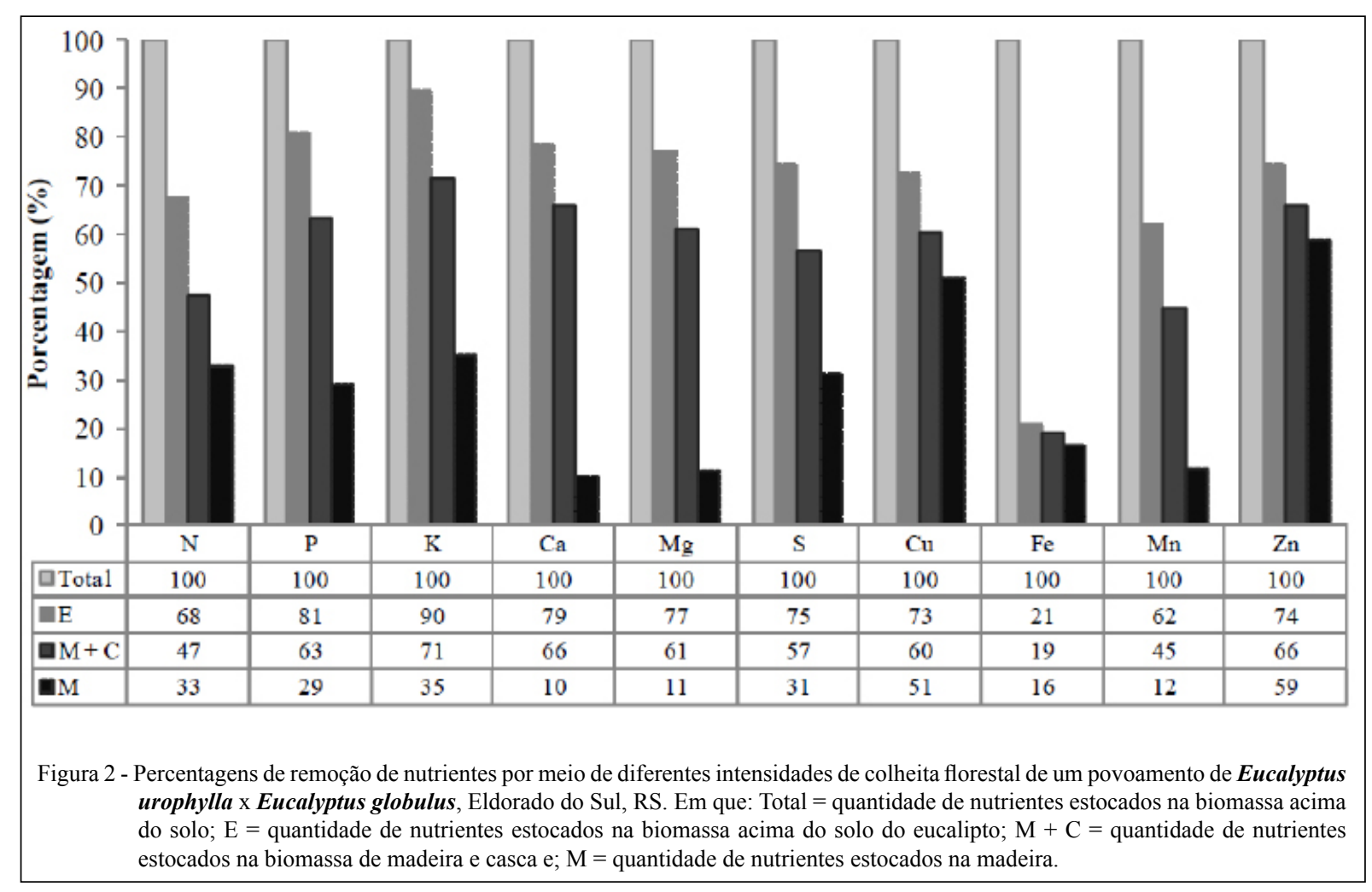

madeira com casca quanto para sem casca, foi similar à verificada por SANTANA et al. (1999), avaliando povoamentos de Eucalyptus grandis e Eucalyptus saligna em diferentes sítios florestais.

Para a produção de todos os componentes da biomassa, os elementos enxofre e fósforo são os macronutrientes mais eficientemente utilizados (Tabela 3). O coeficiente de utilização de macronutrientes da madeira decresceu na seguinte ordem: $\mathrm{P}>\mathrm{S}>\mathrm{Mg}>\mathrm{Ca}>\mathrm{N}>\mathrm{K}$. Essa ordem foi diferente da encontrada por SILVA et al. (1983), para cinco espécies de eucaliptos (Eucalyptus grandis, Eucalyptus saligna, Eucalyptus propinqua, Eucalyptus dunnii e Eucalyptus robusta), e por SANTANA et al. (2002), em três procedências de Eucalyptus grandis e Eucalyptus saligna, sendo que os autores, em ambos os trabalhos, observaram uma magnitude média de: $\mathrm{P}>\mathrm{Mg}>\mathrm{K}>\mathrm{N}>\mathrm{Ca}$. A madeira apresenta os maiores valores do $\mathrm{CUB}$, algo bastante desejável e de grande interesse para a silvicultura, com exceção ao Fe. Nas folhas, estão os menores valores do CUB, com exceção do $\mathrm{Ca}$ e $\mathrm{Mg}$ que estão na casca, indicando a importância da manutenção destes componentes no solo após a colheita. Em relação à eficiência de utilização de micronutrientes, o cobre é o nutriente mais eficientemente utilizado em todos os componentes da biomassa, seguido pelo $\mathrm{Zn}$, Fe e Mn.
A variação na eficiência de utilização de nutrientes pode estar vinculada às características de cada espécie; a não obtenção do equilíbrio nutricional ótimo ou crítico entre solo - planta e todos os demais nutrientes, podendo ocorrer limitação ou excesso de um ou mais nutrientes disponíveis; e às relações hídricas (SANTANA et al., 2002). A alta eficiência apresentada por uma espécie na utilização de nutrientes implica que ela tenha menor exigência nutricional, sendo, portanto, um parâmetro de grande utilidade na seleção de espécies a serem utilizadas nos plantios, principalmente em solos de baixa fertilidade natural (SILVA et al., 1983). Dessa forma, a utilização de técnicas de manejo que optem por plantas mais eficientes em utilizar nutrientes é importante para manter a capacidade produtiva do sítio florestal (SANTANA et al., 2002).

Com isso, devem-se utilizar materiais genéticos que possuam eficiência compatível com a fertilidade do solo, pois, segundo SANTANA et al. (1999), plantas pouco eficientes na absorção de um determinado nutriente deveriam ser implantadas em solos com boa disponibilidade desse nutriente ou recebê-lo via adubação. Ao contrário, se for introduzido um material genético altamente eficiente na absorção de um determinado nutriente em um solo com baixa disponibilidade desse elemento, sem que 
Tabela 3 - Estimativa do número potencial de rotações (NPR) com base no estoque de nutrientes na biomassa e disponíveis no solo (1m de profundidade) e na saída, via colheita da biomassa, da taxa de remoção de nutrientes (TR) e do coeficiente de utilização biológica (CUB), conforme intensidade de colheita da biomassa acima do solo de um povoamento de Eucalyptus urophylla x Eucalyptus globulus, Eldorado do Sul, RS.

\begin{tabular}{|c|c|c|c|c|c|c|c|c|c|}
\hline $\mathrm{N}^{\circ}$ Potencial de rotações & \multicolumn{3}{|c|}{$\mathrm{N}$} & \multicolumn{2}{|l|}{$\mathrm{P}$} & $\mathrm{K}$ & \multicolumn{2}{|l|}{$\mathrm{Ca}$} & $\mathrm{Mg}$ \\
\hline $\mathrm{NPR}_{\text {total }}$ & & 1,3 & & 0,2 & & 1,7 & 0,7 & & 2,5 \\
\hline $\mathrm{NPR}_{\text {eucalipto }}$ & & 2,4 & & 0,5 & & 2,0 & 1,2 & & 3,5 \\
\hline $\mathrm{NPR}_{\text {madeira }}+$ casca & & 3,8 & & 1,0 & & 2,7 & 1,6 & & 4,7 \\
\hline $\mathrm{NPR}_{\text {madeira }}$ & & 5,9 & & 3,3 & & 6,6 & 15,6 & & 29,3 \\
\hline Taxa de remoção & & & & & $\mathrm{K}$ & $\mathrm{Ca}$ & $\mathrm{Mg}$ & & $\mathrm{S}$ \\
\hline $\mathrm{TR}_{\text {total }}$ & & & & & 1,65 & 3,54 & 0,85 & & 0,20 \\
\hline $\mathrm{TR}_{\text {eucalipto }}$ & & & & & 1,62 & 3,05 & 0,72 & & 0,16 \\
\hline $\mathrm{TR}_{\text {madeira }+ \text { casca }}$ & & & & & 1,38 & 2,73 & 0,61 & & 0,13 \\
\hline $\mathrm{TR}_{\text {madeira }}$ & & & & & 0,75 & 0,47 & 0,13 & & 0,08 \\
\hline CUB & $\mathrm{P}$ & $\mathrm{K}$ & $\mathrm{Ca}$ & $\mathrm{Mg}$ & $\mathrm{S}$ & $\mathrm{Cu}$ & $\mathrm{Fe}$ & $\mathrm{Mn}$ & $\mathrm{Zn}$ \\
\hline Madeira & 13285 & 1328 & 2123 & 7874 & 12411 & 524784 & 53555 & 59180 & 206372 \\
\hline Casca & 1273 & 145 & 44 & 205 & 1752 & 317427 & 35600 & 2336 & 195476 \\
\hline Galhos & 2270 & 240 & 119 & 416 & 2713 & 168639 & 56937 & 3196 & 96919 \\
\hline Folhas & 973 & 124 & 154 & 456 & 811 & 148832 & 22861 & 2442 & 141941 \\
\hline
\end{tabular}

receba adubação, ocorrerá diminuição acentuada na capacidade produtiva do sítio.

\section{CONCLUSÃO}

$\mathrm{Na}$ colheita da madeira com casca, todos os nutrientes sofreriam remoção superior a $45 \%$ de sua quantidade acumulada na biomassa total acima do solo. Entretanto, removendo-se apenas a madeira comercial, que apresenta o maior coeficiente de utilização de nutrientes, a porcentagem de remoção para os nutrientes, com exceção do $\mathrm{Cu}$ e do $\mathrm{Zn}$, seria inferior a $50 \%$, chegando a até $10 \%$ no caso do $\mathrm{Ca}$, em relação ao total contido na biomassa.

As principais implicações nutricionais serão causadas pelo fósforo e cálcio, que poderão ser os principais nutrientes a se tornarem limitantes na produtividade nas próximas rotações, pois as estimativas de rotações estão próximas a um, quando considerada a colheita da madeira com casca.

\section{REFERÊNCIAS}

BARROS, N.F. et al. Classificação nutricional de sítios florestais - descrição de uma metodologia. Revista Árvore, Viçosa, v.10, n.1, p.112-120, 1986.

COBB, W.R. et al. Aboveground biomass and nitrogen in four short-rotation woody crop species growing with different water and nutrient availabilities. Forest Ecology and Management, Amsterdam, v.255, n.12, p.4032-4039, 2008. Disponível em:
$<$ http://dx.doi.org/10.1016/j.foreco.2008.03.045>. Acesso em: 11 nov. 2011. doi: doi:10.1016/j.foreco.2008.03.045.

DRUMOND, M.A. et al. Distribuição de biomassa e de nutrientes em diferentes coberturas florestais e pastagem na região do médio Rio Doce-MG. Revista Árvore, Viçosa, v.21, n.2, p.187-199, 1997.

POGGIANI, F.M et al. Indicadores de sustentabilidade das plantações florestais. Série Técnica IPEF, Piracicaba, v.12, n.31, p.33-44, 1998. Disponível em: <http://www.ipef.br/publicacoes/ stecnica/nr31/cap3.pdf>. Acesso em: 10 nov. 2011

SANTANA, R.C. et al. Biomassa e conteúdo de nutrientes de procedências de Eucalyptus grandis e Eucalyptus saligna em alguns sítios florestais do Estado de São Paulo. Scientia Forestalis, Piracicaba, v.56, n.56, p.155-169, 1999. Disponível em: <http://www.ipef.br/publicacoes/scientia/nr56/cap12.pdf $>$. Acesso em: 10 nov. 2011.

SANTANA, R.C. et al. Eficiência de utilização de nutrientes e sustentabilidade da produção em procedências de Eucalyptus grandis e Eucalyptus saligna em sítios florestais do estado de São Paulo. Revista Árvore, Viçosa, v.26, n.4, p.447-457, 2002. Disponível em: <http://dx.doi.org/10.1590/S010067622002000400007>. Acesso em: 15 nov. 2011. doi: 10.1590/ S0100-67622002000400007.

SCHUMACHER, M.V.; POGGIANI, F. Produção de biomassa e remoção de nutrientes em povoamentos de Eucalyptus camaldulensis Dehnh, Eucalyptus grandis Hill ex Maiden e Eucalyptus torelliana f. Muell, plantados em Anhembí, SP. Ciência Florestal, Santa Maria, v.3, n.1, p.9-18, 1993. Disponível em: <http://cascavel.ufsm.br/revistas/ojs-2.2.2/ index.php/cienciaflorestal/article/view/283/148>. Acesso em: 15 out. 2011. 
SILVA, H.D. et al. Biomassa, concentração e conteúdo de nutrientes em cinco espécies de Eucalyptus plantadas em solos de baixa fertilidade. Boletim de Pesquisa Florestal, Colombo, n.6/7, p.9-25, 1983. Disponível em: <http://www.cnpf.embrapa. br/publica/boletim/boletarqv/boletim06_07/hsilva2.pdf $>$. Acesso em: 10 out. 2011 .

SPSS. Statistical package for the social science: programa de computador, ambiente windows. Chicago, 1996. Versão 7.5.1.

STRECK, E.V. et al. Solos do Rio Grande do Sul. 2.ed. Porto Alegre: EMATER/RS, 2008. 222p.
VIERA, M. et al. Nutrientes na serapilheira em um fragmento de floresta estacional decidual, Itaara, RS. Ciência Florestal, Santa Maria, v.20, n.4, p.611-619, 2010. Disponível em: <http:// cascavel.ufsm.br/revistas/ojs-2.2.2/index.php/cienciaflorestal/ article/view/2419>. Acesso em: 25 out. 2011.

VIERA, M. et al. Biomassa e nutrientes removidos no primeiro desbaste de um povoamento de Pinus taeda L. em Cambará do Sul, RS. Revista Árvore, Viçosa, v.35, n.3, p.371-379, 2011. Disponível em: <http://dx.doi.org/10.1590/S010067622011000300001>. Acesso em: 25 nov. 2011. doi: 10.1590/ S0100-67622011000300001. 